Int. J. Dev. Biol. 57: 73-83 (2013)

doi: $10.1387 / \mathrm{ijdb} .120056 \mathrm{ca}$

\title{
Brachyury, Tbx2/3 and sall expression during embryogenesis of the indirectly developing polychaete Hydroides elegans
}

\author{
CESAR ARENAS-MENA* \\ Department of Biology, College of Staten Island and Graduate Center, The City University of New York (CUNY), NY, USA
}

\begin{abstract}
Expression of the transcription factor genes brachyury, $T b \times 2 / 3$ and sallis characterized in detail for the first time in an indirectly developing spiralian with a feeding trochophore. In Hydroides elegans, gut formation proceeds by invagination during embryogenesis and is followed by feedingdependent posterior growth during larval stages. Posterior growth gives rise to the reproductive and segmented portion of the adult and derives primarily from multipotent dorsal blastomeres. Dorsal fate becomes morphologically evident at the 60 -cell stage during spiral cleavage, although the timing of dorsal specification remains uncertain. Expression of brachyury anticipates the morphogenetic events associated with both gastrulation by invagination in the endoderm and ventral midline convergent extension in the ectoderm. The absence of brachyury expression in endoderm precursors previously reported in annelids that do not have feeding larvae suggests evolutionarily conserved roles associated with morphogenesis rather than endoderm specification. Synexpression of brachyury and FoxA in the blastopore of eumetazoans as well as in the secondarily formed anus of some protostomes and the mouth of deuterostomes suggests shared regulatory circuits during the formation of both oral and anal openings in protostomes and deuterostomes. Expression of sall during gastrulation, in the protonephridium, and in posterior growth zone precursors, also suggests evolutionarily conserved roles. The dorsal sides of the Hydroides and sea urchin embryos express $T b \times 2 / 3$ in all three germ layer precursors, suggesting evolutionarily conserved dorsal regionalization functions. The results suggest specific gene usage during tubular gut formation, endoderm specification, dorsoventral specification and anteroposterior body elongation in the context of development by feeding larva.
\end{abstract}

KEY WORDS: indirect development, spiralian, bilaterian body plan evolution, gastrulation, terminal addition

Development by intermediate feeding-trochophore larva of the spiralian polychaete Hydroides elegans provides particular insight into the regulatory entities that control development in spiralians. Modern developmental biology studies have been initiated in various polychaetes that lack a feeding trochophore larva (Irvine \& Martindale 2000; Denes et al., 2007; Frobius et al., 2008). Nevertheless, substantial differences in the way feeding trochophores develop make their study relevant to better understand polychaete development and the evolution of its regulation. The tubular gut of feeding-trochophore larvae of indirectly developing polychaetes is formed by active endoderm invagination during embryogenesis (Fig. 1 a) (Anderson 1966). In contrast, in polychaetes with nonfeeding larvae, the larval "endoderm" is not an epithelium but consists of large cells full of yolk that are passively internalized by overlaying of the ectoderm, a process called epiboly, and the true one-way gut only forms long after the foregut and hindgut epitheliums have formed during non-feeding larval stages (Fig. 1 b) (Anderson 1966; Fischer \& Dorresteijn 2004; Boyle \& Seaver 2008). Polychaetes both with and without feeding larvae have a blastopore that partially closes along the ventral midline (Fig. 1) (Woltereck 1904; Shearer 1911; Anderson 1966; Arenas-Mena et al., 2006; Arenas-Mena \& Wong 2007). Formation of the segmented portion of the body in polychaetes with feeding trochophores primarily derives from small multipotent precursors in the larva and is feeding-dependent (Anderson 1966; Arenas-Mena et al., 2007a) (Fig. 1A). In contrast, polychaetes that lack a feeding trochophore

Abbreviations used in this paper: PGZ, posterior growth zone.

\footnotetext{
*Address correspondence to: Cesar Arenas-Mena. Department of Biology, College of Staten Island, 2800 Victory Boulevard, Staten Island, NY. 10314, USA. Tel: +1-718-982-3869. e-mail: cesar.arenasmena@csi.cuny.edu - web: http://www.library.csi.cuny.edu/ arenas
} 
have large yolky eggs that nourish the immediate proliferation of prominent posterior growth-zone (PGZ) precursors in charge of generating the segmented portion of the adult (Anderson 1966) (Fig 1B). These PGZ precursors derive from $4 \mathrm{~d}$ and $2 \mathrm{~d}$ blastomeres located in the dorsal/posterior side of the embryo. Similar to the early cleavage in other indirectly developing polychaetes with feeding trochophores, the 4-cell embryo of $H$. elegans has blastomeres of equal size: A, B, C and D (Arenas-Mena 2007b); although, it is unknown if the fate of the dorsal quadrant $(D)$ is already specified among these morphologically indistinguishable blastomeres. In clear contrast, the 4-cell embryos of polychaetes without feeding trochophores have a much larger $D$ blastomere with invariable dorsal fates. These differences in developmental processes among polychaetes with feeding and non-feeding larvae should correlate with distinct temporal deployment of regulatory genes involved in posterior growth, gut formation and dorsal specification. In addition, similar gene deployment may exist among distant animals with similar biphasic development involving feeding ciliated larvae.

The transcription factor brachyury is generally involved in gastrulation (Arendt 2004), $T b \times 2 / 3$ is associated with dorsal fate specification in sea urchins (Gross et al., 2003), and sall is associated with posterior growth (Copf et al., 2006) and gastrulation (Materna et al., 2006; Sweetman \& Munsterberg 2006). In this study, the expression of these transcription factors is characterized in the indirectly developing polychaete H. elegans.

\section{Results}

\section{HeSall expression}

The zinc finger transcription factor sall/spalt (sall/salm) has been characterized in several bilaterians, including Drosophila (Copf et al., 1988; Barrio et al., 1996), C. elegans (Toker et al., 2003), vertebrates (Hollemann et al., 1996; Kohlhase et al., 1996; Buck et
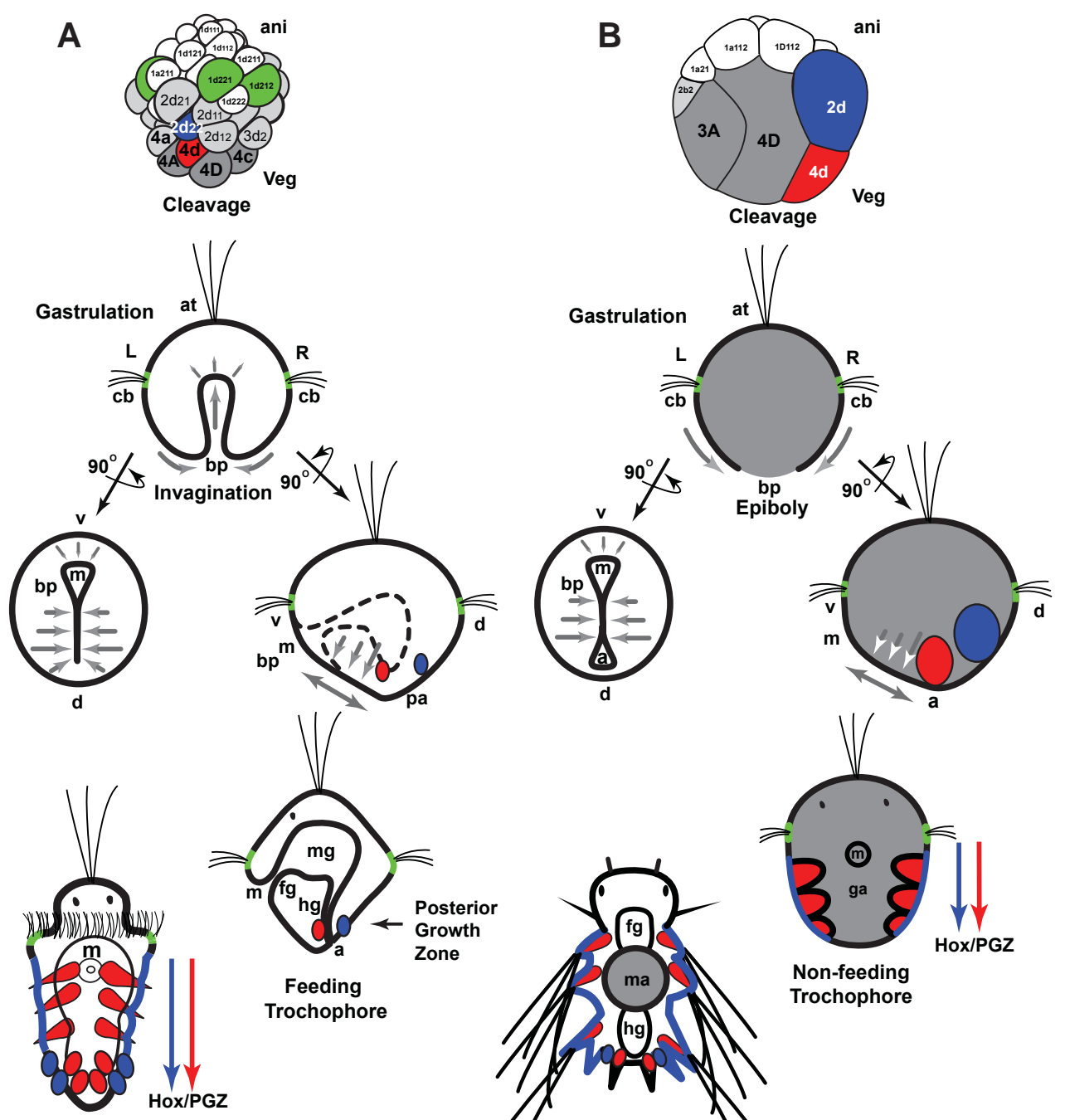

Segmented worm

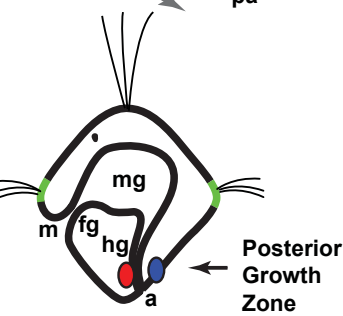

Feeding Trochophore
B

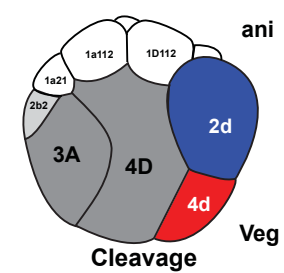

ani

Fig. 1. Comparison of direct and indirect development in polychaetes. (A) Development of an indirectly developing serpulid with feeding trochophore (Hatschek 1885; Shearer 1911; Wisely 1958; Anderson 1966; Arenas-Mena 2006; Arenas-Mena 2007b; Arenas-Mena et al., 2007b). (B) Development of a nereid with non-feeding trochophore (Wilson 1892; Anderson 1966; Arendt 2004; Fischer \& Dorresteijn 2004). First row. Gray and colors denote vegetal hemisphere blastomeres; animal hemisphere blastomeres are in white and green. Embryos depicted at similar size for clarity; the actual relative size of indirectly developing embryos is much smaller (Anderson 1966). Blastomeres fated to midgut (dark gray), posterior growth zone (PGZ) mesoderm (red) and PGZ ectoderm (blue) are of large-size in directly developing nereids, whereas a larger number of blastomeres have larval fates in indirectly developing serpulids. Second row. Gastrulation in indirectly developing polychaetes with feeding trochophore proceeds by active invagination of the endoderm to form the gut epithelium (gastrulation movements indicated by gray arrows). In polychaetes with non-feeding trochophore the passive and yolky endoderm precursors are internalized by epiboly (the ectoderm actively encloses the passive endoderm). Third row. Anal blastopore closure is complete in indirect developers, only the mouth opening remains; in the side view, the internal endoderm is represented by a dashed line; the secondary gut opening (anus) will form after fusion of the ectoderm and endoderm on the dorsal side in the prospective anal region (pa). In both polychaetes there is elongation along the ventral midline by convergent extension of the ectoderm after blastopore closure (double headed arrows). Fourth row. The feeding trochophore of a prototypical indirectly developing serpulid has a functional tripartite gut and precursors of the segmented portion of the worm are inconspicuous (red and blue); only after feeding is the segmented portion formed by posterior growth (fifth row). The non-feeding trochophore of a prototypic nereid lacks a functional epithelial gut. Its endoderm consists of compact and yolky cells that form the gut anlage (ga); posterior growth during non-feeding larval stages starts during embryogenesis. Incipient crawling worms of direct developers still lack feeding capability, and nourishment remains dependent on the yolky midgut anlage (ma). Blastomere designations as previously summarized (Anderson 1966; Arenas-Mena 2007b). a, anus; at, apical tuft; bp, blastopore; cb, ciliary band; d, dorsal; fg, foregut; hg, hindgut; $L$, left; $m$, mouth; mg, midgut; 0 , oral; pa, prospective anus; $R$, right; PGZ, posterior growth zone; v, ventral. 
al., 2001) and an indirectly developing sea urchin (Materna et al., 2006). Virtual translation of a cDNA isolated from $H$. elegans by PCR methods reveals a polypeptide sequence having clear affinity with Sall/Salm zinc finger transcription factors (also known as sal and spalt) (Fig. 2).

Expression of $\mathrm{HeSall}$ is first detected in all four 2q2 blastomeres of 52-cell embryos (Fig. 3A); at this stage, a, b, c and d quadrants are indistinct (Arenas-Mena 2007a), and are jointly designated as q for quadrant. The simultaneous nuclear staining (Fig. 3E) allows unambiguous identification of the cleavage stage, which has been characterized in detail up to the 80-cell stage (Arenas-Mena 2007b). During later stages, identified by chromatin condensation that anticipates the division of 2 q2 blastomeres, HeSallexpression is also seen in all four 3q2 blastomeres (Fig. 3B). Subsequently, there is a decline in expression in $2 q 2$ blastomeres and their descendants (Fig. 3K, and optical sections not shown). Therefore, there is a shift in gene expression from more animal $2 q 2$ blastomeres to more vegetal and adjacent $3 q 2$ blastomeres. The $3 q 2$ expression is more robust in 60-cell embryos (Fig. 3C). In recently formed 64-cell embryos, expression now includes blastomeres adjacent to 3q2, that is, in 3q1 and 2q22 blastomeres (Fig. 3D). In more advanced 64-cell embryos, when chromatin is fully decondensed (Fig. 3I), a decline in expression is observed in $3 \mathrm{~d} 1$ and $2 \mathrm{a} 21$ (out of focus in Fig. 3I), which occupy nearly symmetrical positions relative to the sagittal plane. During incipient gastrulation stages, a ring of expression is seen in blastomeres that occupy the prospective blastopore rim (Fig. 3J). The central blastomeres, which do not express HeSall (Fig. 3J), start to ingress into the blastocoel (serial optical sections not shown); during this stage the identity of individual cells in the prospective blastopore cannot be unambiguously assigned, because gastrulation movements start to blur the invariant spiral-cleavage pattern that has been characterized up to the 80-cell stage (Arenas-Mena 2007a). Nevertheless, the HeSallexpressing ring of cells seems to include all $3 q 2$ descendants and at least some of the $2 a-c 22$ descendants. Blastomeres $4 q$ and $2 d 22$ express the gene during late cleavage stages (Fig. 3 L,Q). The blastopore-associated expression of $\mathrm{HeSall}$ is maintained during early gastrulation stages (Fig. 4 A,E). During later gastrulation stages, the expression declines first from the left and right flanks of the blastopore and remains high in the oral and aboral sides of the blastopore (Fig. 4 B,F). Eventually, the expression further declines in the oral-side blastopore cells but remains high in the aboral-side blastopore cells (Fig. 4 C,D,G). During these early gastrulation stages, the HeSall-expressing blastomeres apparently derive from blastomeres expressing the gene during the invariant spiral cleavage (Fig. $4 \mathrm{H}$ ). The dynamic expression of HeSall around the blastopore rim is suggestive of morphogenetic functions associated with gastrulation. Similar association of sall expression with gastrulation was previously described in vertebrates and sea urchins (Materna et al., 2006; Sweetman \& Munsterberg 2006), suggesting an evolutionarily conserved morphogenetic role.

HeSall is later expressed in putative protonephridium precursors flanking foregut precursors (Fig. 4I) and in their presumptive descendants in trochophore stages (Fig. $4 \mathrm{M}-\mathrm{O}$ ). The expression is rarely seen on the left and right sides simultaneously, suggesting transient and/or oscillatory expression (Fig. 4 I). The protonephridia are thought to derive from left and right ectomesoderm derivatives that form a strand by proliferation toward the anal region (Shearer 1911). The HeSall-expressing cells flanking the foregut (Fig. 4 M,N) apparently differentiate into the elongated protonephridium cells of early trochophore larvae (Fig. 4O). The expression of HeSall in protonephridium precursors has counterparts in other bilaterians; sall is involved in complex morphogenetic events related to the formation of diverse tubular organs in Drosophila and vertebrates. In vertebrates, one of the sall paralogs has an essential role in metanephros development by mediating ureteric tube interactions with nephron mesenchyme precursors (Nishihanakamura \& Osafune 2006) (Farrell et al., 2001), and, in the Drosophila tracheal system, sall is downstream of Wingless, and its absence specifically disrupts dorsal branches (Chihara \& Hayashi 2000). The expression of $\mathrm{HeSall}$ described here would be compatible with developmental functions in the excretory organs of the polychaete larva, which would represent conservation of more general functions in nephridial precursors and tubular organ development in bilaterians.

HeSallis later expressed in cells that, by their position, are identified as PGZ precursors (4d and $2 \mathrm{~d} 22$ descendants) that contribute to form the segmented portion of the adult. After aboral blastopore closure the number of mesenchyme cells expressing HeSall on the aboral side increases (Fig. 4 G-K), perhaps by proliferation of

A

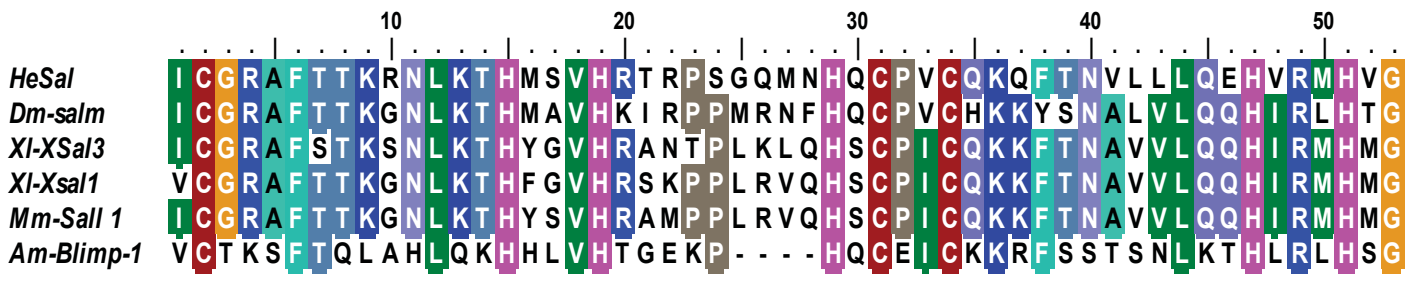

B
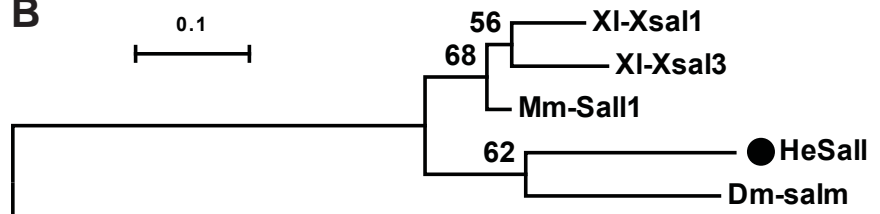

Am-blimp-1
Fig. 2. Sequence analysis of HeSall. The sequence of HeSall is similar to other Sall orthologs. The sequence of the Asterina miniata Blimp/ Krox gene is used as the outgroup to root the tree. (A) Alignment of Sall proteins using ClustalW. (B) Phylogenetic tree derived from maximum likelihood analysis of the sequence region shown in a. Branch lengths are proportional to the number of changes indicated by the scale. Percent of bootstrap values above $50 \%$ supporting the respective nodes after 1000 replications are shown. The following sequences were used for the alignment: HeSall, gi|JX457836|; Am-blimp1, gi|37781470|; XI-Xsal1, gi|1235931|; Dm-salm (spalt, sal), gi|2598394|; XI-Xsal-3, gi|6172236|; Mm-Sall 1 gi|38566278|; Am, Asterina miniata; Dm, Drosophila Melanogaster; Mm, Mus musculus; XI, Xenopus laevis. 


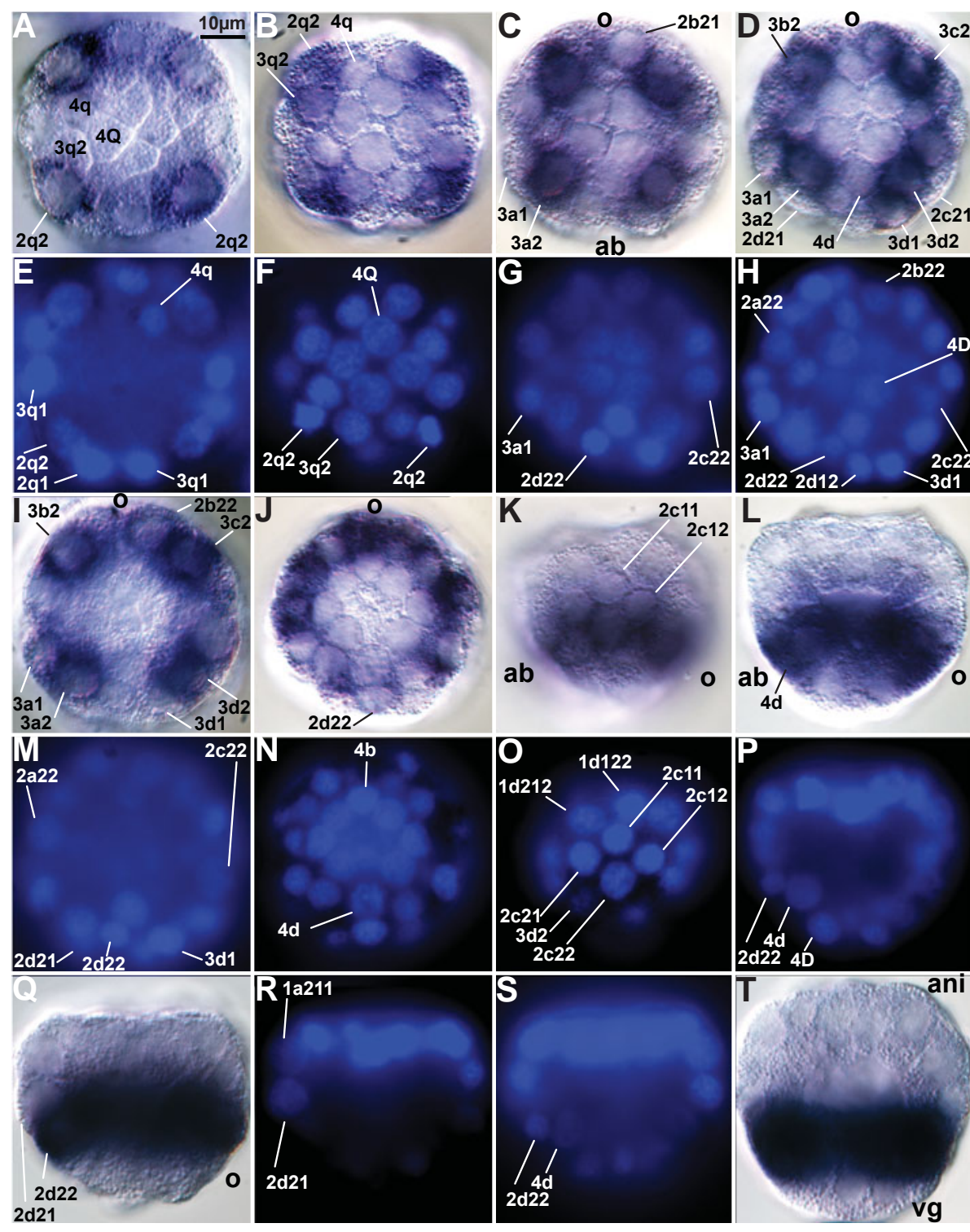

Fig. 3. Expression of HeSall mRNA during cleavage. DIC optical sections a-d and $i-l$ with their corresponding nuclear staining e-h and $m-p$. (A) Animal cap view of a 52-cell embryo at the level of the vegetal hemisphere. Scale bar for this and subsequent panels. (B) 52-cell embryo just before the division of 2q2. (C) Animal cap view of a 60-cell embryo at the level of the vegetal hemisphere. (D) Animal cap view of a 64-cell embryo at the level of the vegetal hemisphere. (I) 64-cell embryo at a later stage than the embryo in d. (J) Vegetal view of an embryo with more than 80 cells, before gastrulation. (K) Lateral view of a 64-cell embryo. (L) Optical medial section of the embryo shown in $k$. (Q) Optical section of a 68-cell embryo. (R) Nuclear staining of q. (S) Consecutive optical section of r. (T) Optical medial section of a blastula embryo with more than 80 cells, at a stage similar to the embryo in j. Superscript has been omitted to improve readability. ab, aboral; ani, animal; vg, vegetal.

already expressing cells. These cells are associated with ectoderm cells that also express HeSall (Fig. 4L). The ectoderm of the PGZ of the trochophore larva expresses HeSall in bilaterally distributed cells (Fig. 4O, double arrowhead and 4P, arrowheads).

\section{Brachyury expression}

Brachyury is a T-box family transcription factor associated with morphogenetic functions across bilaterians and cnidarians (Arendt 2004). Brachyury is involved in convergent extension rear- rangements during gastrulation in bilaterians (Arendt 2004), including convergent extension rearrangements during the formation of the sea urchin tubular gut (Hardin 1989). The corresponding gene, $\mathrm{HeBra}$, was isolated in $H$. elegans (Fig. 5), and its expression is also found to be associated with gastrulation. Expression of HeBrais first detected in blastomeres that lead gastrulation by invagination, first in the four central vegetal blastomeres (Fig. 6A) and then in the adjacent peripheral blastomeres (Fig. 6 B-D). Subsequently, $\mathrm{He}$ Bra expression declines in the central vegetal blastomeres while it is further enhanced in the peripheral blastomeres, with particular emphasis in the four 3q2 blastomeres (Fig. 6 $\mathrm{C}-\mathrm{E})$. This centrifugal sequence of activation followed by deactivation continues during gastrulation and results in transient $\mathrm{HeBra}$ expression in cells that enter and leave the blastopore during invagination (Fig. 6 F-N). Thus, the expression declines in cells that are about to invaginate. HeBra expression in central vegetal blastomeres declines faster in the ventral-side blastomeres than in the dorsal-side blastomeres (Fig. 6 E-H). This dorso-ventral asymmetry of expression correlates with the greater contribution to endoderm by the ventral side of the vegetal plate (Anderson 1966; Arenas-Mena et al., 2006; Arenas-Mena \& Wong 2007), which contributes to the upward shift of the blastopore from its originally central-vegetal position (Fig. $6 \mathrm{~N}-\mathrm{R}$ ). The generalized endodermal expression of HeBracorrelates with the complex morphogenetic process of gastrulation by invagination, which is consistent with its demonstrated role in morphogenesis rather than endoderm specification as seen in sea urchins (Gross \& McClay 2001).

The expression of $\mathrm{HeBra}$ is also associated with morphogenetic events in the ectoderm. During the final stages of gastrulation, $\mathrm{HeBra}$ is found in the left and right ectodermal flanks (Fig. $6 \mathrm{G}-\mathrm{N}$ ) down to the blastopore lips that will eventually merge to seal the ectoderm (not the endoderm) along the ventral midline (Fig. 6 $L, M)$. The initial range of expressing cells has a crescent shape with the broadest section in the ventral midline. The expressing cells generally correspond to the area that apparently rearranges by means of convergent-extension cell rearrangements that separate the mouth from the prospective anus in $H$. elegans and other indirectly developing polychaetes with a feeding trochophore (Anderson 1966; Arenas-Mena 2006). Convergent extension in the ventral midline also moves the prospective mouth away from the prospective anus in the polychaete Platynereis dumerilii, and is similarly associated with the expression of brachyury (Steinmetz et al., 2007). This second ectodermal phase of expression does have a counterpart in the ventral midline expression during the 
epibolic gastrulation of the annelid $P$. dumerilii (Arendt et al., 2001) and the gastropod Patella vulgata (Lartillot 2002). In contrast, the early endodermal phase does not have a counterpart in the yolky and passive endoderm precursors of $P$. dumerilii (Arendt et al., 2001) and P. vulgata (Lartillot 2002), further emphasizing a morphogenetic role rather than a germ layer-specification role of brachyury. Thus expression of brachyury in $H$. elegans could be said to have earlier endodermal and later ectodermal phases, which are continuous in space and time and correlate with extensive morphogenetic rearrangements.

\section{HeTbx2/3 expression}

The transcription factor $\mathrm{HeTbx2/3}$ is expressed in the dorsal half of the embryo in ectodermal, endodermal and mesodermal precursors through development (Fig. 7). Dorsally restricted HeTbx2/3staining is robust and generalized in 64-cell embryos (Fig. 7A). Expression is initially detected in a few blastomeres occupying the dorsal midline (Fig. 7 A-D). Later in development, the expression remains centered in the dorsal midline, but is broader and also includes additional blastomeres in the animal and vegetal hemispheres (Fig. $7 \mathrm{E}-\mathrm{H}$ ). The intensity of staining declines in vegetal areas during gastrulation, although general dorsal restriction continues during gastrulation in all three germ-layer precursors (Fig. 7 I-M), with a slight rightward bias in the endoderm during early gastrulation and enhanced expression in cells at the dorsal side of the archenteron and abutting ectoderm (Fig. 7 I-M). In early trochophore larvae, expression remains high in dorsal-side apical sensory organ cells (Fig. 7N), dorsal endodermal cells (Fig. $7 \mathrm{~N}-\mathrm{P}$ ), putative posterior sensory organ precursors (Fig. 7 O,P) and adjacent hindgut (Fig. 7P). Tbx2/3 has general dorsal expression in a directly developing hemichordate (Lowe et al., 2006), and Tbx2/3 is expressed in the dorsal ganglia and optic cup of Xenopus embryos (Hayata et al., 1999). The expression of HeTbx2/3 is generally similar to the expression reported for the corresponding gene in indirectly developing sea urchins, where it is expressed in aboral (dorsal) precursors of all three germ layers and has morphogenetic roles (Gross et al., 2003). The expression of HeTbx2/3 is compatible with a similar dorsal specification role in the embryo of Hydroides.

\section{Discussion}

The expression of genes associated with gastrulation is regulated differently in embryos that generate
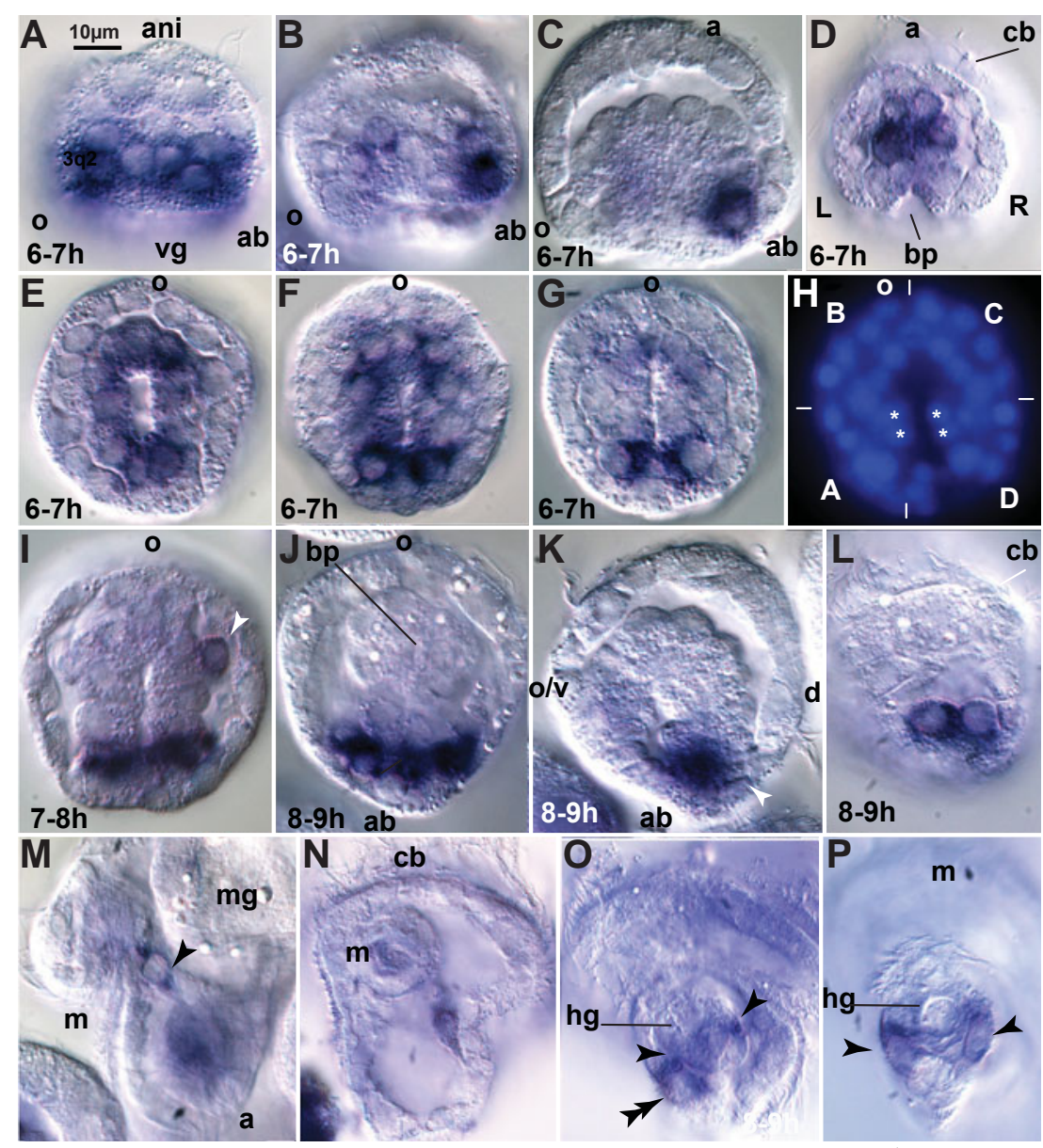
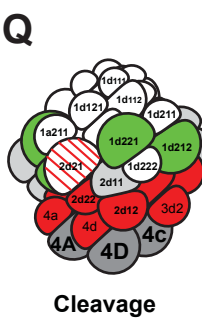

64-cell
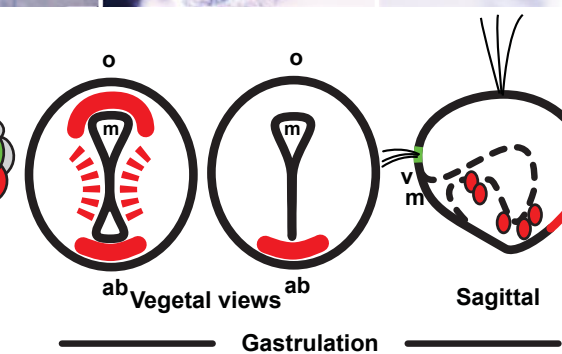

\section{$\mathbf{R}$} $-$

Fig. 4. Expression of HeSall mRNA during gastrulation. (A) Lateral view of an early gastrula embryo. Central blastomeres already ingressed into the blastocoel. The blastopore orientation, oral to the left, is deduced from its typical rounded shape on the oral side. (B) Lateral view of a gastrulating embryo more advanced than the one shown in a. (C) Lateral optical section of a gastrulating embryo more advanced than the embryo in b. (D) Embryo at a stage similar to that of the embryo in $\mathrm{C}$, seen from the aboral side of the blastopore. (E-G) Blastopore view of embryos at stages similar to those in a-c, respectively. (H) Nuclear staining view of the embryo in $\mathrm{g}$. Asterisks mark merging blastomeres in the blastopore side flanks. Letters and thin lines mark approximate spiral cleavage quadrant boundaries. (I) Oblique optical section intersecting mesenchyme cells flanking prospective foregut precursors, white arrowhead. (J). Optical section of an embryo by the end of gastrulation (after aboral blastopore closure) that intersects foregut and hindgut precursors. (K) Lateral view of a late gastrula embryo. (L) Dorsal surface view of a late gastrula embryo. (M) Lateral view of a 24-hour-old trochophore. Putative protoneprhidium precursor indicated by arrowhead. (N) Oblique optical section intersecting putative protonephridium precursors. (0) Optical section of a more developed trochophore. Arrowheads point to elongated tubular protonephridium cells flanking the hindgut. Double arrowhead points to an ectoderm cell in the PGZ. (P) Optical section at the level of the PGZ. Arrowheads point to ectoderm cells. (Q) Diagrammatic summary of HeSall expression (in red) as indicated. Line filling and dashed lines signify declining expression. See text for detailed description. Oral and aboral designations are restricted to the blastopore and dorsal and ventral extend to the whole embryo-larva, see previous diagrams (Arenas-Mena 2006; Arenas-Mena 2007b; Arenas-Mena et al., 2007b). a, anus; ab, aboral; ani, animal; bp, blastopore; cb, ciliary band; $d$, dorsal; fg, foregut; hg, hindgut; $L$, left; $m$, mouth; mg, midgut; o, oral; $R$, right; v, ventral; vg, vegetal. 
A

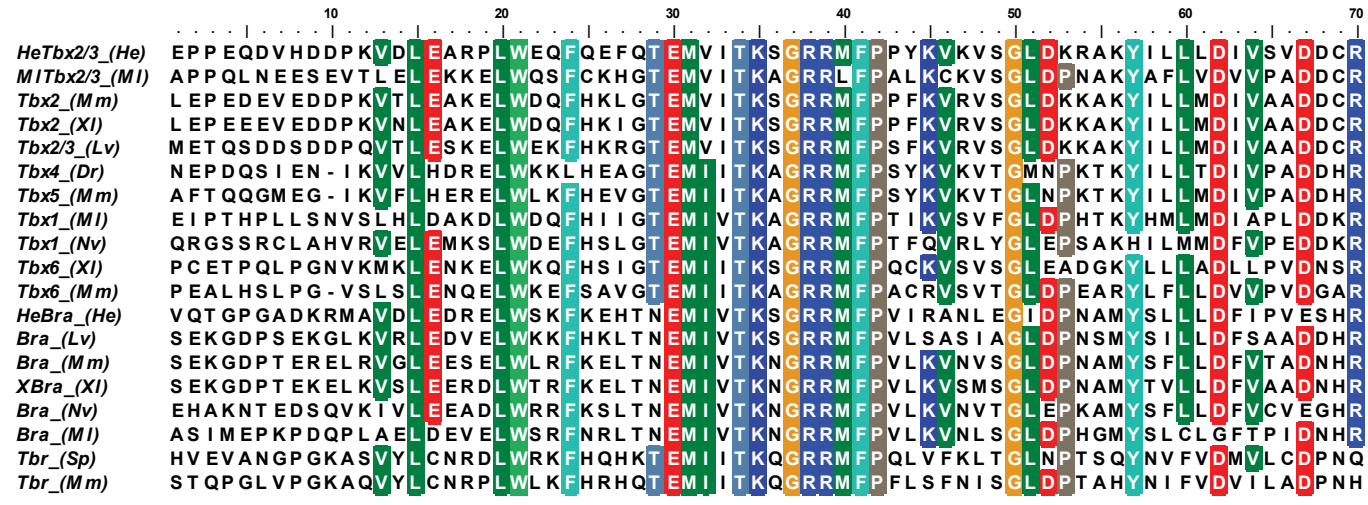

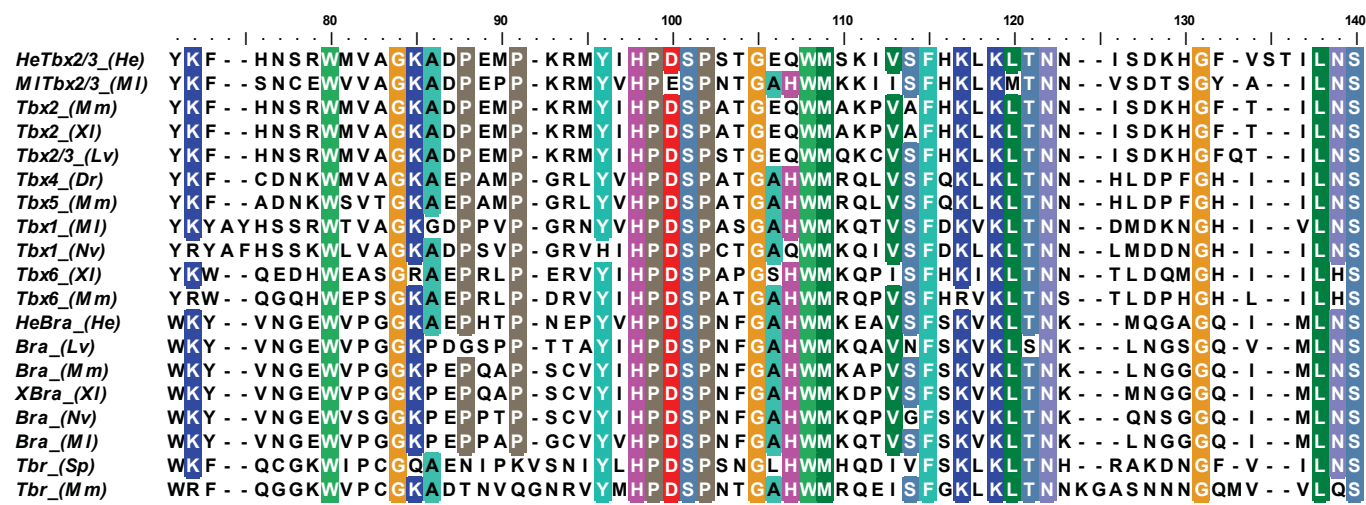

HeTbx2/3_(He) $M I T b \times 2 / 3 \_$(MI) $T b \times 2$ _ $(M m)$ TbX2_(XI)

$T b \times 2 / 3 \_(L v)$

Tbx4_(Dr) Tbx5_(M m) Tbx1_(MI)

Tbx1 $(N v)$

Tbxi_(Nv)

Tbx6_(XI)

Tbx6_(Mm)

HeBra_(H

Bra_(Lv)

Bra_(Mm)

$X B r a \_(X I)$

Bra_(Nv)

Bra_(MI)

Tbr_(Sp)

Tbr_(M m)
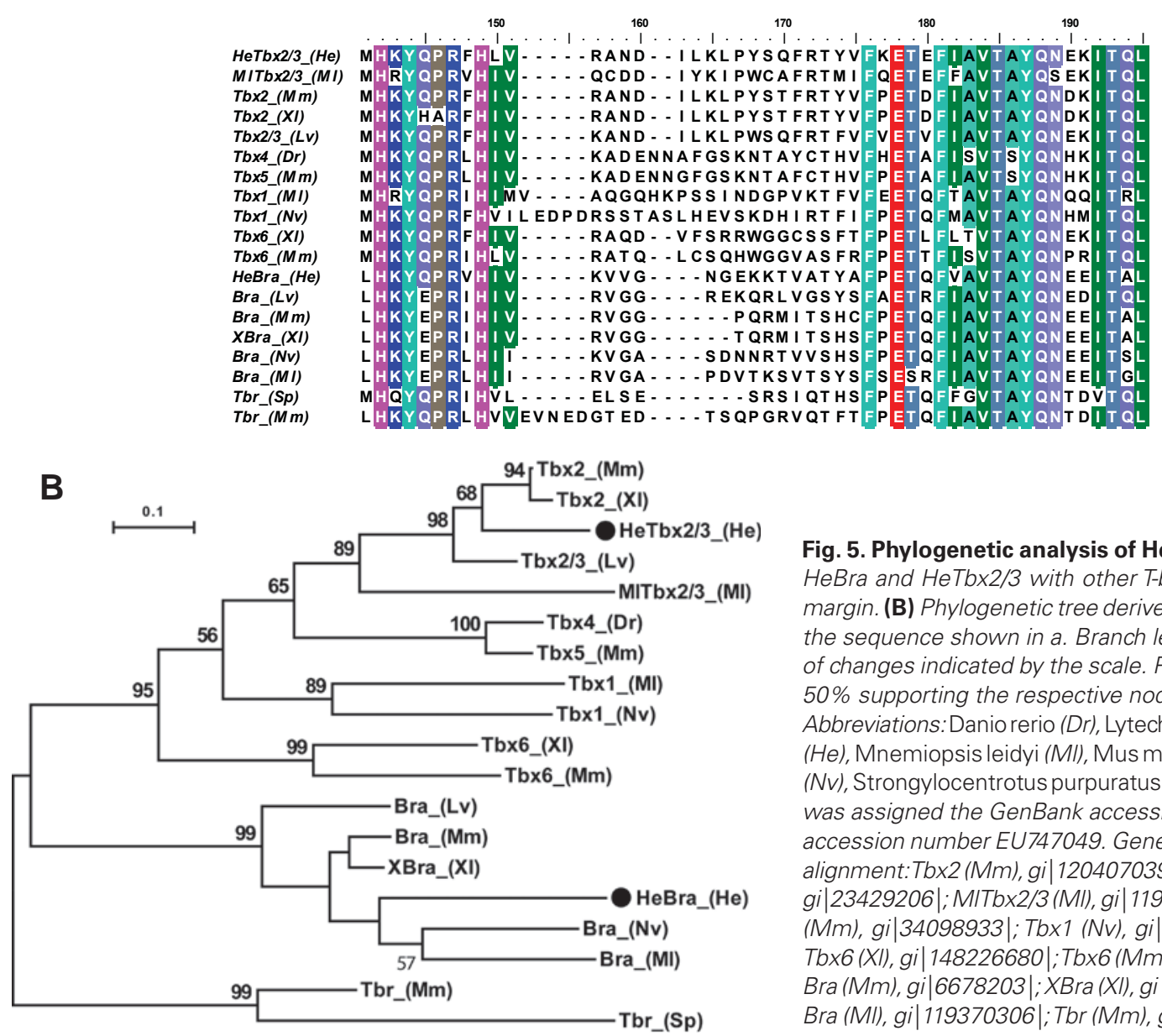

Fig. 5. Phylogenetic analysis of HeBra and HeTbx2/3. (A) Alignment of $\mathrm{HeBra}$ and HeTbx2/3 with other T-box subfamily groups indicated in the margin. (B) Phylogenetic tree derived from maximum likelihood analysis of the sequence shown in a. Branch lengths are proportional to the number of changes indicated by the scale. Percentages of bootstrap values above $50 \%$ supporting the respective nodes after 3000 replications are shown. Abbreviations: Danio rerio (Dr), Lytechinus variegatus ( $L v$ ), Hydroides elegans $(\mathrm{He})$, Mnemiopsis leidyi (MI), Mus musculus ( $\mathrm{Mm})$, Nematostella vectensis (Nv), Strongylocentrotus purpuratus (Sp), and Xenopus laevis (XI). HeTbx2/3 was assigned the GenBank accession number EU747048, and HeBra the accession number EU747049. Gene identifiers for the proteins used in the alignment:Tbx2 (Mm), gi|120407039|;Tbx2 (XI), gi|148236619|;Tbx2/3 (Lv), gi|23429206|;MITbx2/3 (MI), gi|119370313|;Tbx4 (Dr), gi|18859455|;Tbx5 (Mm), gi|34098933|; Tbx1 (Nv), gi|33621856|; Tbx1 (MI), gi|119370310|; Tbx6 (XI), gi|148226680|;Tbx6 (Mm), gi|48928035|; Bra (Lv), gi|1675550|; $\operatorname{Bra}(\mathrm{Mm})$, gi|6678203|;XBra (XI), gi|147902820|;Bra (Nv), gi|122058623|; Bra (MI), gi|119370306|; Tbr (Mm), gi|34328151|;Tbr (Sp), gi|115955121|. 
feeding versus non-feeding larvae, as would be expected by their distinct gastrulation modes (Fig. 1). The expression of HeBra and HeSall reported here is associated with morphogenetic processes of gastrulation. Similarly, the transcription factors HeFoxA (ArenasMena 2006), HeOtx, HeBlimp and HeT-Brain previously reported (Arenas-Mena \& Wong 2007; Arenas-Mena 2008) also have dy- namic expression during gastrulation by invagination in $H$. elegans. The synexpression of brachyury, Otx and FoxAduring gastrulation by invagination was probably present in the most recent common ancestor of bilaterians and cnidarians, because similarly dynamic blastoporal expression has been reported in the sea anemone Nematostella vectensis (Fritzenwanker et al., 2004; Mazza et al.,
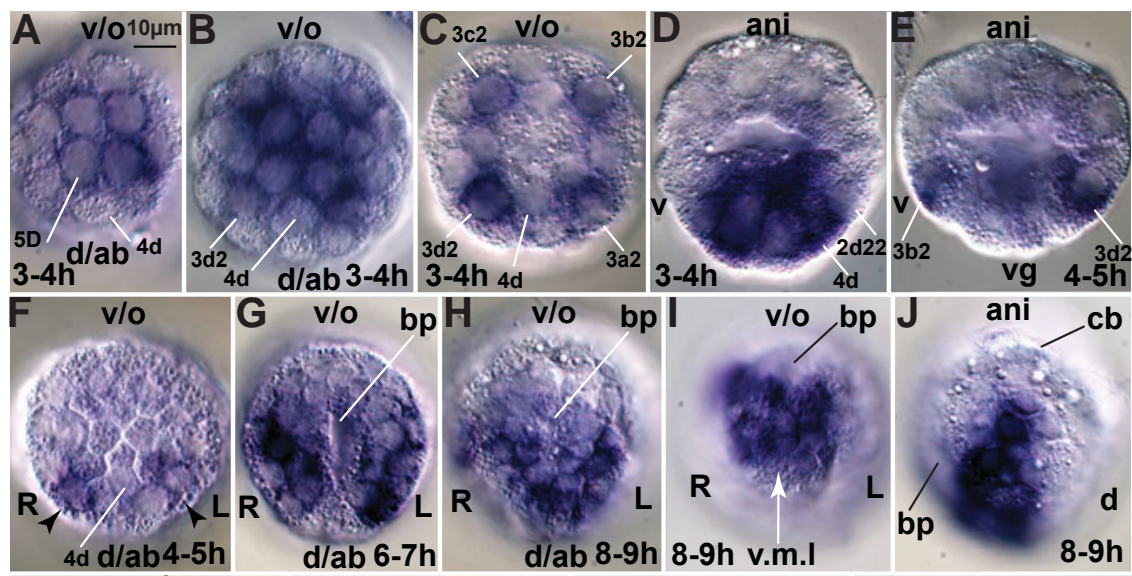

ani
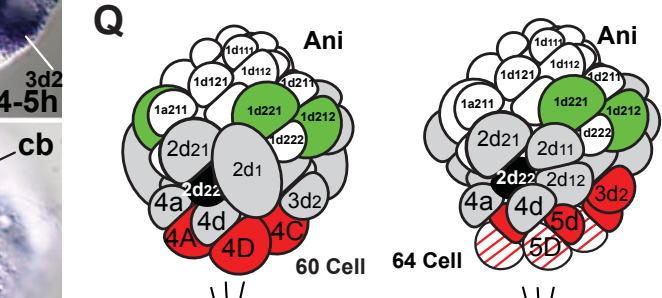

d
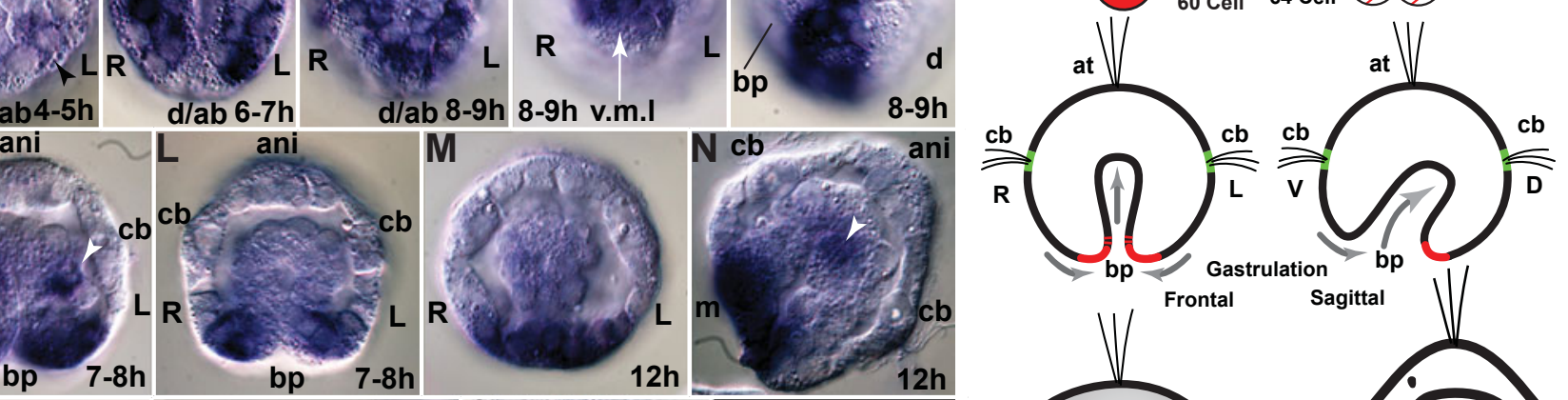

$12 \mathrm{~h}$
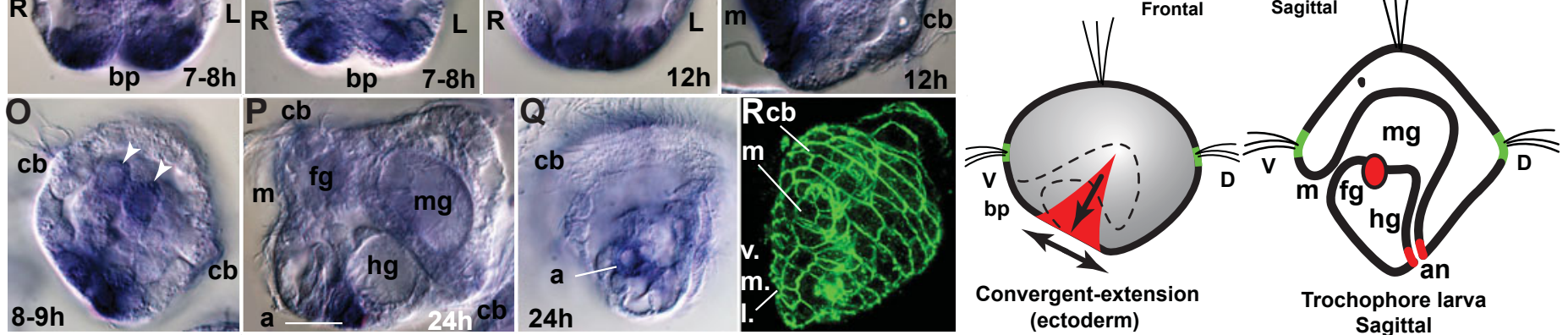

Convergent-extension (ectoderm)

Trochophore larva Sagittal

Fig. 6. HeBra mRNA expression during embryonic and early trochophore larval stages. For nomenclature and reconstruction of blastomere designations consult our previous report (Arenas-Mena 2007b). Nuclear staining required for blastomere designations not shown. Citations refer to further anatomical descriptions. (A) 60-cell embryo shows staining in vegetal 40 blastomeres. Scale bar for this and subsequent panels. (B) $64-c e l l ~ e m b r y o$ with expression in 5Q, $5 q$ and $3 q 2$ blastomeres. (C) 64-cell embryo with declining 50 (out of focus) and $5 q$ expression and strong expression in $3 q 2$ blastomeres. Staining in oral-side blastomeres $3 a 2$ and $3 b 2$ is lighter than staining in aboral-side blastomeres $3 a 2$ and $3 d 2$. (D) Nearly sagittal section of a 64-cell embryo. (E) Oblique optical section of a 68-cell embryo that has already lost expression in 50 and $5 q$ blastomeres. Expression declines in ventral-side $3 b 2$ (and 3c2, out of focus), but remains high in $3 d 2$ (and 3a2, out of focus). (F) 72-cell embryo seen from the vegetal hemisphere. Expression is detected in aboral-vegetal blastomeres in the left and right flanks, arrowheads. (G) Early gastrula embryo. Expression is detected in left and right cells that flank the aboral side of the blastopore. $\mathbf{( H )}$ Embryo where the anal side of the blastopore has already closed and the oral side remains open in the future mouth. (I) Detail of the blastopore lips merging at the center of the blastopore in the prospective ventral midline. (J) Side view shows the extent of HeBra expression in the left and right ectodermal flanks which, through convergent extension in the ventral midline (v.m.l, indicated by the white arrow), contributes to the separation of the anus from the mouth (Anderson 1966; Arenas-Mena 2006). (K) Detail of a gastrulating embryo shows a pair of cells that maintain the expression after invagination, arrowheads; these cells probably adopt a mesenchymal fate and correspond to those labeled by arrowheads in $n$ and o. (L) Transversal optical section of an early gastrula embryo at the level of the prospective foregut shows the expression in the blastopore and the lack of expression in epithelial endoderm. (M) Transversal section after midline ectodermal blastopore closure and epithelial endoderm formation. (N) Side view of a late gastrula embryo. The mouth is still adjacent to the area of the prospective anus. Arrowhead, staining from a mesenchymal cell is out of focus. (0) Detail of expressing cells that apparently adopt mesodermal fates associated with the midguthindgut juncture. (P) 24-hour-old trochophore larva exhibits expression in the anus. (Q) Detail of anal expression in an oblique-transversal section. (R) Cellular surface staining using a $\beta$-catenin antibody illustrates the cellular structure of the ventral midline and mouth of a 24-hour trochophore larva. (S) Diagrammatic summary of HeBra expression (in red) as indicated. Line filling and dashed lines signify declining expression. First row from left to right, 60- and 68-cell embryos; second row, gastrulating embryo, in frontal (left) and sagittal (right) sections (sagittal section similar to the embryo sown in I); third row, left, side view of gastrulating embryo, ectodermal expression indicated in red and ectodermal cell rearrangements indicated by arrows (similar view to the embryo shown in j). Third row, right, diagram of trochophore larva, sagittal section (similar view to the larva in p). a, anus; ab, aboral; ani, animal; at, apical tuft; bp, blastopore; cb, ciliary band; $D$, dorsal; fg, foregut; hg, hindgut; L, left; m, mouth; mg, midgut; o, oral; $R$, right; $V$, ventral; vg, vegetal; v.m.l., ventral midline. 

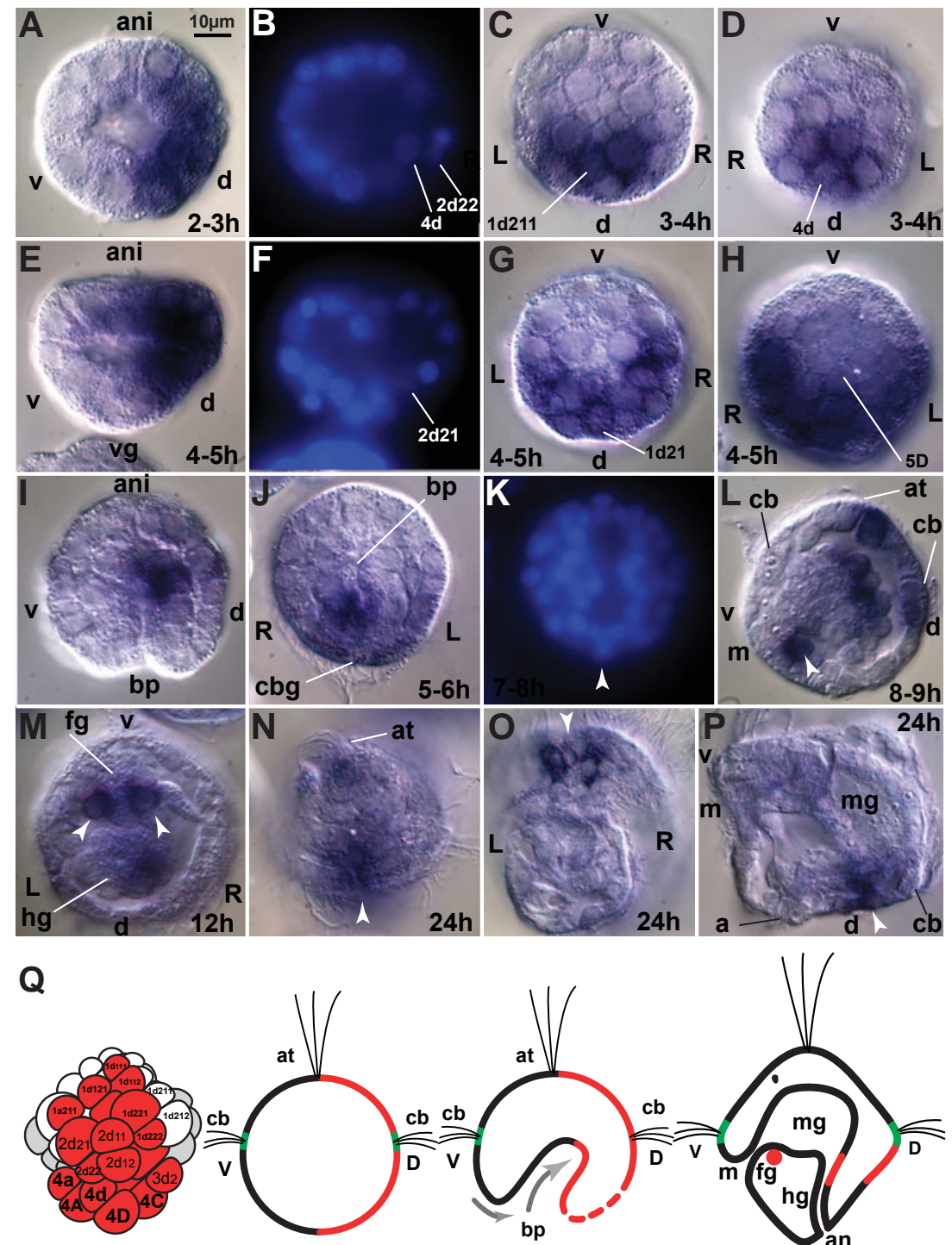

Cleavage Dorsal view

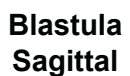

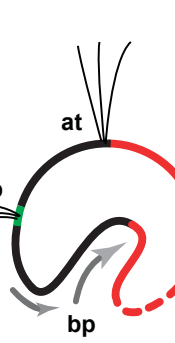

Gastrula Sagittal

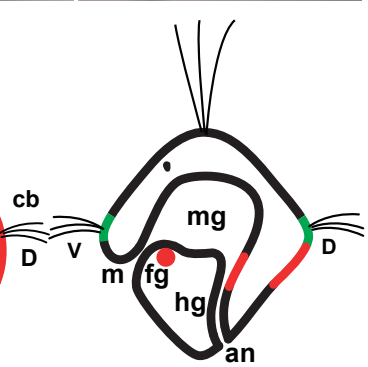

Larva
Sagittal
Fig. 7. HeTbx2/3 mRNA expression during embryonic and early trochophore larval stages. For nomenclature and reconstruction of blastomere designations consult our previous report (Arenas-Mena 2007b). Serial optical sections and nuclear staining required for blastomere designations not shown. (A) Sagittal optical section of a 64-cell embryo. (B) Nuclear staining of the embryo in a. (C) Animal cap view of a 64-cell embryo. (D) Vegetal view of a 64-cell embryo. (E) Nearly sagittal view of a 72-cell embryo. Expression is clearly associated with the dorsal side of the embryo, which is morphologically distinct (Arenas-Mena 2007b). (F) Nuclear staining of the embryo in e. (G) Animal cap of a 72-cell embryo. The expression has expanded or increased in the left and right flanks. (H) Vegetal view of a 68-cell embryo; similar lateral expansion is observed on the vegetal side. (I) Nearly sagittal optical section shows expression in endodermal and ectodermal precursors on the dorsal-animal side. The expression has declined in cells in the blastopore area. (J) Vegetal view of a gastrulating embryo. The expression remains restricted to dorsal ectodermal and endodermal precursors with a slightly broader domain of expression on the right side. (K) Nuclear staining of the embryo in j. Arrowhead points to the ciliary band gap (c.b.g) in the dorsal midline. The 8-shaped blastopore is merging at the middle. (L) Slightly oblique optical section. The expression continues in ectodermal, mesodermal and endodermal precursors. The dorsal-most cell of the apical tuft has particularly strong staining. A couple of putative protoneprhidium precursors (Arenas-Mena 2006) flanking the foregut express the gene, arrowhead. (M) Transversal section shows the bilateral arrangement of putative mesenchymal precursors, arrowheads, and the asymmetric expression in the forming hindgut. (N) Animal cap view. The dorsal-most apical tuft cells maintain HeTbx expression. Cells adjacent to the ciliary band gap (arrowhead) maintain the expression. (0) Dorsal-vegetal view. Putative posterior sensory organ precursors (Arenas-Mena \& Wong 2007) express the gene. Arrowhead, ciliary band gap. (P) Sagittal optical section reveals expression that remains in differentiated dorsal ectoderm and adjacent hindgut of a 24-hour trochophore larva. (0) Diagrammatic summary of HeTbx2/3 expression (in red) as indicated. an, anus; ani, animal; at, apical tuft; bp, blastopore; cb, ciliary band; c.b.g, ciliary band gap; $D$, dorsal; fg, foregut; $h g$, hindgut; $L$, left; $m$, mouth; $m g$, midgut; $R$, right; $V$, ventral; vg, vegetal.
2007). In contrast, endodermal expression of brachyury is absent in polychaetes without feeding trochophores that do not form a one-way gut by invagination during embryogenesis. Expression of brachyury in endodermal precursors has not been detected in the passive yolky "endoderm" that is internalized by epibolic gastrulation in the mollusk $P$. vulgata (Lartillot 2002) or the polychaete $P$. dumerilii(Arendt et al., 2001) during the formation of its non-feeding trochophore larva. Similarly, the embryonic endodermal expression of HeOtxobserved in $\mathrm{H}$. elegans (Arenas-Mena \& Wong 2007) has not been detected in the yolky "endoderm" of $P$. dumerilii (Arendt et al., 2001). In contrast, hemichordates and sea urchins with feeding larvae exhibit a dynamic sequence of activation followed by deactivation of brachyury in a ring of endodermal precursors during gastrulation by invagination (Tagawa et al., 1998; Gross \& McClay 2001), similar to the pattern of brachyury expression in $H$. elegans. Therefore, the evolutionary comparison of gene expression confirms a conserved morphogenetic role, rather than a conserved role in germ layer specification, of brachyury.
Brachyury and FoxA form an evolutionarily conserved synexpression group in the blastopore of protostomes, deuterostomes and cnidarians (Fritzenwanker et al., 2004). Both in Hydroides and sea urchin embryos, the areas of endoderm and ectoderm that will fuse to form the respective secondary gut openings are also anticipated by FoxA expression (Arenas-Mena 2006; Oliveri et al., 2006). Furthermore, brachyuryexpression is maintained during the early larval stages in the hindgut/anus of Hydroides (Fig. 6P) and foregut/mouth of sea urchins (Gross \& McClay 2001). Therefore, it seems that Brachyury and FoxA are required at the boundary of endoderm and ectoderm during the formation of both mouth and anus in protostomes and deuterostomes (Fig. 8).

The expression of HeSall in the PGZ suggests there are ancestral regulatory roles associated with posterior growth, which may include conserved Hox cluster gene regulatory functions. Hox cluster gene expression is associated with patterning and controlling anteroposterior elongation across bilaterians, but Hox cluster expression is relegated to the postembryonic feeding-dependent 


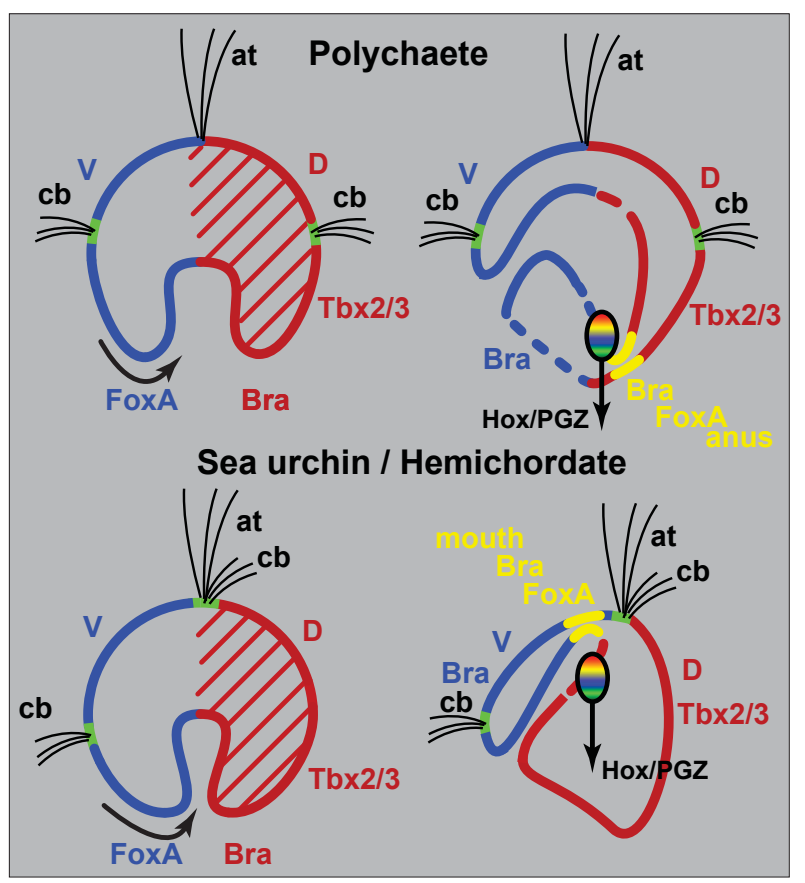

Fig. 8. Developmental similarities between embryos of indirectly developing sea urchins, hemichordates and polychaetes. The transcription factors indicated have polarities in their blastopore expression that are similar between polychaetes and sea urchins; the color boundaries in the diagrams do not always signify gene expression domains. The black arrows symbolize oral-aboral morphogenetic asymmetries during gastrulation. Tbx2/3 exhibits generalized dorsal expression in the animal and vegetal hemispheres. Development of the secondary archenteron opening is preceded by FoxA expression in the ectoderm and endoderm that will eventually fuse (yellow); brachyury expression is maintained in the secondary gut opening during early larval stages (yellow). Brachyury persists longer in the dorsal side (auburn) of the blastopore. Dashed lines in the emerging larvae indicate regions that likely originate after cell rearrangements across initial dorsal-ventral subdivisions. The multicolored circles indicate the position of adult mesodermal precursors whose proliferation results in growth along the anteroposterior direction, indicated by the arrow that symbolizes the Hox/PGZ vector. at, apical tuft; cb, ciliary band; $D$, dorsal; $V$, ventral.

phase and does not participate in the formation of ciliated larvae during the embryogenesis of deuterostomes (Arenas-Mena et al., 1998; Arenas-Mena 2010) and protostomes (Irvine \& Martindale 2000; Peterson et al., 2000) (Fig. 8). The regulatory functions of sall and Hox transcription factors apparently overlap and/or interact during developmental processes in several bilaterians. In Drosophila, salm is involved in the regional specification of head and tail structures in conjunction with Hox genes (Kuhnlein et al., 1994; Toker et al., 2003); in chicken, sall is expressed in the tail bud (Farrell et al., 2001); in C. elegans, a posterior role of a sall homolog is mediated by repression of the posterior Hox gene egl-5 (Jurgens 1988); in the crustacean Artemia franciscana, sall depletion triggers derepression of various Hox genes in the PGZ (Copf et al., 2006). The expression of Hox cluster genes has not been characterized in Hydroides, but extrapolation from previous characterizations in nereids (Kulakova et al., 2007) anticipates their expression in the $\mathrm{PGZ}$ or in immediate derivatives.

HeSall is associated both with gastrulation and PGZ precursors, but the developmental processes involved do not seem continuous in space and time. Gastrulation and anteroposterior elongation are clearly independent from each other in bilaterians with feeding ciliated larvae (Fig. 8). Gut formation precedes posterior growth in polychaetes with feeding larva. On the contrary, in polychaetes without feeding larvae, posterior growth precedes gut formation, which is postponed to late larval stages (Fig. 1). Accordingly, the embryos of polychaetes without feeding larvae have a relatively larger investment in adult fates, and enlarged $4 \mathrm{~d}$ and $2 \mathrm{~d}$ adult precursors that form the proliferative PGZ during embryogenesis (Fig. 1B), whereas the embryos of polychaetes with feeding larvae have a relatively larger investment in larval fates: nearly all blastomeres contribute to the larva except for the small blastomeres $4 d$ and $2 d$ that contribute primarily to the adult during the feeding-dependent developmental phase (Fig. 1A). The distinction between gastrulation and posterior growth may not be so apparent in polychaetes without feeding trochophores because posterior growth is initiated during embryogenesis (Anderson 1966). Platynereis is a polychaete without a feeding trochophore, and it has been shown that its early elongation along the ventral midline proceeds by convergent extension (Steinmetz et al., 2007). Nevertheless, it remains uncertain if the simultaneously initiated posterior growth is a continuation of the midline convergent extension or a completely different developmental process in Platynereis.

The expression of $T b \times 2 / 3$ suggests the possibility of ancestral regulatory entities that subdivide protostome and deuterostome embryos into homologous ventral and dorsal sides (Fig. 8). The dorsal expression of $\mathrm{HeTb} 2 / 3$ in all three germ layers is similar to the expression reported in sea urchins where its morphogenetic function has been demonstrated (Gross et al., 2003). Similarly, the ventral side of the blastopore also has a clear bias for the expression of the transcription factor FoxA in $H$. elegans and in indirectly developing sea urchins (Arenas-Mena 2006; Oliveri et al., 2006). Furthermore, protostome (Arendt et al., 2001) and deuterostome (Duboc et al., 2004) embryos express the transcription factor goosecoid in their the ventral-oral side, and in sea urchins goosecoid represses Tbx2/3 expression (Croce et al., 2003). The nerve chord is dorsal in chordates and ventral in many protostomes, and it has been suggested that regulatory gene usage favors their homology (Denes et al., 2007), although alternative interpretations have been proposed (van den Biggelaar et al., 2002). The BmpChordin system in charge of setting dorsoventral specifications is also present in ciliated larvae of protostomes and deuterostomes and it is similarly involved in neural cell-type specifications in sea urchin embryos that, nevertheless, do not contribute to a central nerve chord (Angerer et al., 2000; Yaguchi et al., 2006). The signaling ligand Bmp2/4 is expressed in the ventral (oral) side of sea urchin embryos, but its overexpression promotes dorsal (aboral) fates (Angerer et al., 2000). Therefore, Bmp2/4 remains a dorsalpromoting signal in the larval context of protostomes (Denes et al., 2007) and deuterostomes (Duboc et al., 2004), although its source originates from dorsal and ventral sides, respectively. Thus the functions and expression of $B m p 2 / 4$ and Tbx2/3apparently relate to dorsoventral specification systems that seem generally conserved between protostome and deuterostomes. Nevertheless, because there is no obvious equivalent of a nerve chord in protostome and deuterostome larvae, this dorsoventral specification system should be distinct from regulatory entities controlling the formation of nerve chords in protostomes and deuterostomes when present.

The modular nature of development (Carroll 2001) allows the 
independent evolution of developmental processes. Tubular gut formation, endoderm specification, dorsoventral specification, neural tube development and anteroposterior body elongation are associated with particular sequences of regulatory gene deployment in the context of feeding and non-feeding larval development among bilaterians. Future functional analysis will decipher the regulatory entities controlling these processes and perhaps allow their evolutionary reconstruction along lineages leading to indirect and direct development (Sly et al., 2003).

\section{Materials and Methods}

Protocols, reagents and methods utilized in this manuscript have been previously described (Arenas-Mena 2006; Arenas-Mena \& Wong 2007), including the sequences of degenerate primers against conserved T-box and zinc finger sequences used for PCR-based cloning (Arenas-Mena 2006). Whole Mount In situ Hybridization (WMISH) methods also have been described previously (Arenas-Mena 2006; Arenas-Mena \& Wong 2007). In short, embryos were fixed in 0.1 M MOPS pH 7, 0.5 M NaCl, and $4 \%$ formaldehyde for $3 \mathrm{~h}$ at room temperature. After five washes in at least 10 volumes of $0.1 \mathrm{M}$ MOPS, $0.5 \mathrm{M} \mathrm{NaCl}$ and $0.1 \%$ Tween-20 (MOPS buffer), the samples were stored indefinitely in $70 \%$ ethanol at $-20^{\circ} \mathrm{C}$. Rehydration in MOPS buffer was followed by a 3-hour prehybridization at $50^{\circ} \mathrm{C}$ in a solution of $70 \%$ deionized formamide, $0.5 \mathrm{M} \mathrm{NaCl}, 0.1 \mathrm{M} \mathrm{MOPS}(\mathrm{pH}$ 7), $0.1 \mathrm{mg} / \mathrm{ml} \mathrm{BSA}$ and $0.1 \%$ Tween-20. Hybridization was performed in the same buffer with digoxigenin-UTP-labeled probes at $0.1 \mathrm{ng} / \mu \mathrm{l}$ for one week at $50^{\circ} \mathrm{C}$. Excess probe was removed after 3 washes in MOPS buffer with a 3-hour incubation under hybridization conditions. The samples were blocked with $10 \mathrm{mg} / \mathrm{ml} \mathrm{BSA}$ in MOPS buffer for 20 minutes at room temperature and then with $10 \%$ goat serum plus $1 \mathrm{mg} / \mathrm{ml} \mathrm{BSA}$ at $37^{\circ} \mathrm{C}$ for 30 minutes in MOPS buffer. Incubation of anti-digoxigenin Fab fragments conjugated to alkaline phosphatase (Roche Molecular Biochemicals, Indianapolis, IN) was done at 1/2000 dilution, and the samples were developed in NBT/BCIP buffer until sufficient contrast of staining was obtained. Simultaneous nuclear staining of the embryos with DAPI and visualization of multiple optical serial sections (not shown) revealed in each case the blastomere designations indicated in the figures according to the invariant spiral cleavage previously described in this species (Arenas-Mena 2007b). Additional diagrams that help understand the anatomy of $H$. elegans and its invariant cleavage can be found in previous publications (Arenas-Mena 2006; Arenas-Mena 2007b; Arenas-Mena et al., 2007b).

\section{Acknowledgements}

I would like to thank Kimberly Suk-Ying Wong and Leila Lager for their assistance during the preparation of reagents and data collection. Thanks also to Daryl Henderson for comments and suggestions that helped improve the manuscript.

\section{References}

ANDERSON, D. T. (1966) The comparative embryology of the Polychaeta. Acta Zool (Stockh.) 47: 1-42.

ANGERER, L. M., OLEKSYN, D. W., LOGAN, C. Y., MCCLAY, D. R., DALE, L., ANGERER, R. C. (2000) A BMP pathway regulates cell fate allocation along the sea urchin animal-vegetal embryonic axis. Development 127: 1105-1114.

ARENAS-MENA, C. (2006) Embryonic expression of HeFoxA1 and HeFoxA2 in an indirectly developing polychaete. Dev Genes Evol 216: 727-736.

ARENAS-MENA, C. (2007a) Developmental transcriptional-competence model for a histone variant and a unicellular origin scenario for transcriptional-multipotency mechanisms. Evol Dev 9: 208-211.

ARENAS-MENA, C. (2007b) Sinistral equal-size spiral cleavage of the indirectly developing polychaete Hydroides elegans. Dev Dyn 236: 1611-1622.

ARENAS-MENA, C. (2008) The Transcription Factors HeBlimp and HeT-Brain of an
Indirectly Developing Polychaete SuggestAncestral Endodermal, Gastrulation, and Sensory Cell-Type Specification Roles. J Exp Zool B Mol Dev Evo/310B: 567-576.

ARENAS-MENA, C. (2010) Indirect development, transdifferentiation and the macroregulatory evolution of metazoans. Philos Trans R Soc Lond B Biol Sci365:653-669.

ARENAS-MENA, C., WONG, K. S.-Y. (2007) HeOtx expression in an indirectly developing polychaete correlates with gastrulation by invagination. Dev Genes Evol 217: 373-384

ARENAS-MENA, C., CAMERON, R. A., DAVIDSON, E. H. (2006) Hindgut specification and cell-adhesion functions of $s p H o x 11 / 13 b$ in the endoderm of the sea urchin embryo. Dev Growth Differ 48: 463-472.

ARENAS-MENA, C., SUK-YING WONG, K., R. ARANDI FOROSHANI, N. (2007a) Histone H2A.Z expression in two indirectly developing marine invertebrates correlates with undifferentiated and multipotent cells. Evol Dev 9: 231-243.

ARENAS-MENA, C., WONG, K. S.-Y., ARANDI-FOROSHANI, N. (2007b) Ciliary band gene expression patterns in the embryo and trochophore larva of an indirectly developing polychaete. Gene Expression Patterns 7: 544-549.

ARENAS-MENA, C., MARTINEZ, P., CAMERON, R. A., DAVIDSON, E. H. (1998) Expression of the Hox gene complex in the indirect development of a sea urchin. Proc. Natl. Acad. Sci. USA 95: 13062-13067.

ARENDT, D. (2004) Comparative aspects of gastrulation. In: Stern, C. D. (ed.) Gastrulation: from cells to embryo. Cold Spring Harbor Laboratory Press, New York.

ARENDT, D., TECHNAU, U., WITTBRODT, J. (2001) Evolution of the bilaterian larval foregut. Nature 409: 81-85

BARRIO, R., SHEA, M. J., CARULLI, J., LIPKOW, K., GAUL, U., FROMMER, G. T., SCHUH, R., JÃCKLE, H., KAFATOS, F. C. (1996) The spalt-related gene of Drosophila Melanogaster is a member of an ancient gene family, defined by the adjacent, region-specific homeotic gene spalt. Dev Genes Evol 206: 315-325.

BOYLE, M. J., SEAVER, E. C. (2008) Developmental expression of foxA and gata genes during gut formation in the polychaete annelid, Capitella sp I. Evol Dev 10: 89-105.

BUCK, A., KISPERT, A., KOHLHASE, J. (2001) Embryonic expression of the murine homologue of SALL1, the gene mutated in Townes-Brocks syndrome. Mech Dev 104: $143-146$

CARROLL, S. B. (2001) Chance and necessity: the evolution of morphological complexity and diversity. Nature 409: 1102-1109.

CHIHARA, T., HAYASHI, S. (2000) Control of tracheal tubulogenesis by Wingless signaling. Development 127: 4433-4442.

COPF, T., RABET, N., AVEROF, M. (2006) Knockdown of spalt function by RNA causes de-repression of Hox genes and homeotic transformations in the crustacean Artemia franciscana. Dev Biol 298: 87-94.

COPF, T., RABET, N., CELNIKER, S., AVEROF, M. (1988) Head and tail development of the Drosophila embryo involves spalt, a novel homeotic gene. EMBOJ.7:189-196.

CROCE, J., LHOMOND, G., GACHE, C. (2003) Coquillette, a sea urchin T-box gene of the Tbx2 subfamily, is expressed asymmetrically along the oral-aboral axis of the embryo and is involved in skeletogenesis. Mech Dev 120: 561-572.

DENES, A. S., JEKELY, G., STEINMETZ, P. R. H., RAIBLE, F., SNYMAN, H., PRUD'HOMME, B., FERRIER, D. E. K., BALAVOINE, G., ARENDT, D. (2007) Molecular architecture of annelid nerve cord supports common origin of nervous system centralization in bilateria. Cell 129: 277-288.

DUBOC, V., ROTTINGER, E., BESNARDEAU, L., LEPAGE, T. (2004) Nodal and BMP2/4 signaling organizes the oral-aboral axis of the sea urchin embryo. Dev Cell 6: 397-410

FARRELL, E. R., TOSH, G., CHURCH, E., MUNSTERBERG, A. E. (2001) Cloning and expression of CSAL2, a new member of the spalt gene family in chick. Mech Dev 102: 227-230.

FISCHER, A., DORRESTEIJN, A. (2004) The polychaete Platynereis dumerilii (Annelida): a laboratory animal with spiralian cleavage, lifelong segment proliferation and a mixed benthic/pelagic life cycle. BioEssays 26: 314-325.

FRITZENWANKER, J. H., SAINA, M., TECHNAU, U. (2004) Analysis of forkhead and snail expression reveals epithelial-mesenchymal transitions during embryonic and larval development of Nematostella vectensis. Dev Biol 275: 389-402.

FROBIUS, A. C., MATUS, D. Q., SEAVER, E. C. (2008) Genomic Organization and Expression Demonstrate Spatial and Temporal Hox Gene Colinearity in the Lophotrochozoan Capitella sp I. Plos One 3.

GROSS, J. M., MCCLAY, D. R. (2001) The Role of Brachyury (T) during Gastrulation 
Movements in the Sea Urchin Lytechinus variegatus. Dev Biol 239: 132-147.

GROSS, J. M., PETERSON, R. E., WU, S. Y., MCCLAY, D. R. (2003) LvTbx2/3: a T-box family transcription factor involved in formation of the oral/aboral axis of the sea urchin embryo. Development 130: 1989-1999.

HARDIN, J. (1989) Local Shifts in Position and Polarized Motility Drive Cell Rearrangement During Sea-Urchin Gastrulation. Dev Biol 136: 430-445.

HATSCHEK, B. (1885) Entwicklung der trochophora von Eupomatus uncinatus. Arbt. Zool Inst Wien vi: 121.

HAYATA, T., KURODA, H., EISAKI, A., ASASHIMA, M. (1999) Expression of Xenopus T-box transcription factor, Tbx2 in Xenopus embryo. Dev Genes Evol209: 625-628.

HOLLEMANN, T., SCHUH, R., PIELER, T., STICK, R. (1996) Xenopus Xsal-1, a vertebrate homolog of the region specific homeotic gene spalt of Drosophila. Mech Dev 55: 19-32.

IRVINE, S. Q., MARTINDALE, M. Q. (2000) Expression patterns of anterior Hox genes in the polychaete Chaetopterus: Correlation with morphological boundaries. Dev Biol 217: 333-351.

JURGENS, G. (1988) Head and tail development of the Drosophila embryo involves spalt, a novel homeotic gene. EMBO J 7: 189 -196.

KOHLHASE, J., SCHUH, R., DOWE, G., KUHNLEIN, R. P., JACKLE, H., SCHROEDER, B., SCHULZ-SCHAEFFER, W., KRETZSCHMAR, H. A., KOHLER, A., MULLER, U., RAAB-VETTER, M., BURKHARDT, E., ENGEL, W., STICK, R. (1996) Isolation, Characterization, and Organ-Specific Expression of Two Novel Human Zinc Finger Genes Related to the Drosophila Gene Spalt. Genomics 38: 291-298.

KUHNLEIN, R., FROMMER, G., FRIEDRICH, M., GONZALEZ-GAITAN, M., WEBER, A., WAGNER-BERNHOLZ, J., GEHRING, W., JACKLE, H., SCHUH, R. (1994) spalt encodes an evolutionarily conserved zinc finger protein of novel structure which provides homeotic gene function in the head and tail region of the Drosophila embryo. EMBO J. 13: 168-79.

KULAKOVA, M., BAKALENKO, N., NOVIKOVA, E., COOK, C. E., ELISEEVA, E., STEINMETZ, P. R. H., KOSTYUCHENKO, R. P., DONDUA, A., ARENDT, D., AKAM, M., ANDREEVA, T. (2007) Hox gene expression in larval development of the polychaetes Nereis virens and Platynereis dumerilii (Annelida, Lophotrochozoa). Dev Genes Evol 217: 39-54.

LARTILLOT, N., LE GOUAR, M, ADOUTTE, A. (2002) Expression patterns of fork headand goosecoid homologues in the mollusc Patella vulgata supports the ancestry of the anterior mesendoderm across Bilateria. Dev Genes Evol212: 551-61.

LOWE, C. J., TERASAKI, M., WU, M., FREEMAN, R. M., RUNFT, L., KWAN, K., HAIGO, S., ARONOWICZ, J., LANDER, E., GRUBER, C., SMITH, M., KIRSCHNER, M., GERHART, J. (2006) Dorsoventral patterning in hemichordates: Insights into early chordate evolution. Plos Biology 4: 1603-1619.

MATERNA, S. C., HOWARD-ASHBY, M., GRAY, R. F., DAVIDSON, E. H. (2006) The $\mathrm{C} 2 \mathrm{H} 2$ zinc finger genes of Strongylocentrotus purpuratus and their expression in embryonic development. Dev Biol 300: 108-120.

MAZZA, M. E., PANG, K., MARTINDALE, M. Q., FINNERTY, J. R. (2007) Genomic organization, gene structure, and developmental expression of three clustered otx genes in the sea anemone nematostella vectensis. J Exp Zool B Mol Dev Evol 308B: 494-506.

NISHIHANAKAMURA, R., OSAFUNE, K. (2006) Essential Roles of Sall Family Genes in Kidney Development. J Physiol Sc 56: 131-136.

OLIVERI, P., WALTON, K. D., DAVIDSON, E. H., MCCLAY, D. R. (2006) Repression of mesodermal fate by foxa, a key endoderm regulator of the sea urchin embryo. Development 133: 4173-4181.

PETERSON, K. J., IRVINE, S. Q., CAMERON, R. A., DAVIDSON, E. H. (2000) Quantitative assessment of Hox complex expression in the indirect development of the polychaete annelid Chaetopterus sp. Proc. Natl. Acad. Sci. USA 97: 4487-4492.

SHEARER, C. M. A. (1911) On the development and structure of the trochophore of Hydroides (Eupomatus) uncinatus. Quart J micr Sci 56: 543-590.

SLY, B. J., SNOKE, M. S., RAFF, R. A. (2003) Who came first larvae or adults? origins of bilaterian metazoan larvae. Int J Dev Biol. 47: 623-32.

STEINMETZ, P. R. H., ZELADA-GONZALES, F., BURGTORF, C., WITTBRODT, J., ARENDT, D. (2007) Polychaete trunk neuroectoderm converges and extends by mediolateral cell intercalation. Proc. Natl. Acad. Sci. USA 104: 2727-2732.

SWEETMAN, D., MUNSTERBERG, A. (2006) The vertebrate spalt genes in development and disease. Dev Biol 293: 285-293.

TAGAWA, K., HUMPHREYS, T., SATOH, N. (1998) Novel pattern of Brachyury gene expression in hemichordate embryos. Mech Dev 75: 139-143.

TOKER, A. S., TENG, Y., FERREIRA, H. B., EMMONS, S. W., CHALFIE, M. (2003) The Caenorhabditis elegans spalt-like gene sem- 4 restricts touch cell fate by repressing the selector Hox gene egl-5 and the effector gene mec-3. Development 130: 3831-3840.

VAN DEN BIGGELAAR, J. A. M., EDSINGER-GONZALES, E., SCHRAM, F. R. (2002) The improbability of dorso-ventral axis inversion during animal evolution, as presumed by Geoffroy Saint Hilaire. Contributions Zool. 71: 29-36.

WILSON, E. B. (1892) The cell lineage of Nereis. J Morph 6: 361-480.

WISELY, B. (1958) The development and settling of a serpulid worm Hydroides norvegica Gunnerus (Polychaeta). Aust J Mar Freshwater Res 9: 351-361.

WOLTERECK, R. (1904) Beitra"ge zur praktischen Analyse der Polygordius-Entwicklung nach dem "Nordsee-" und dem'Mittelmeer-Typus". Arch Entw Mech Org 18: 377-403.

YAGUCHI, S., YAGUCHI, J., BURKE, R. D. (2006) Specification of ectoderm restricts the size of the animal plate and patterns neurogenesis in sea urchin embryos. Development 133: 2337-2346. 


\section{Further Related Reading, published previously in the Int. J. Dev. Biol.}

Modeling pattern formation in hydra: a route to understanding essential steps in development Hans Meinhardt

Int. J. Dev. Biol. (2012) 56: 447-462

Ciona intestinalis Noto4 contains a phosphotyrosine interaction domain and is involved in the midline intercalation of notochord cells Shigehiro Yamada, Naoto Ueno, Nori Satoh and Hiroki Takahashi

Int. J. Dev. Biol. (2011) 55: 11-18

An organizing region in metamorphosing hydrozoan planula larvae - stimulation of axis formation in both larval and in adult tissue Melanie Stumpf, Britta Will, Karola Wittig, Jennifer Kasper, Benjamin Fischer, Jürgen Schmich, Stefanie Seipp and Thomas Leitz Int. J. Dev. Biol. (2010) 54: 795-802

Comparison of Lim1 expression in embryos of frogs with different modes of reproduction Michael Venegas-Ferrín, Norihiro Sudou, Masanori Taira and Eugenia M. del Pino Int. J. Dev. Biol. (2010) 54: 195-202

The N-terminus zinc finger domain of Xenopus SIP1 is important for neural induction, but not for suppression of Xbra expression

Kazuhiro R. Nitta, Shuji Takahashi, Yoshikazu Haramoto, Masakazu Fukuda, Kousuke Tanegashima, Yasuko Onuma and Makoto Asashima

Int. J. Dev. Biol. (2007) 51: 321-325

$\mathrm{XSu}(\mathrm{H}) 2$ is an essential factor for gene expression and morphogenesis of the Xenopus gastrula embryo

Motoaki Ito, Tomohisa Katada, Seiji Miyatani and Tsutomu Kinoshita

Int. J. Dev. Biol. (2007) 51:27-36

Acceleration of early chick embryo morphogenesis by insulin is associated with altered expression of embryonic genes

Vidya Patwardhan, Madhavi Gokhale and Surendra Ghaskadbi

Int. J. Dev. Biol. (2004) 48: 319-326

Origin and evolution of endoderm and mesoderm

Ulrich Technau and Corinna B Scholz

Int. J. Dev. Biol. (2003) 47: 531-539

Characterization of novel F-actin envelopes surrounding nuclei during cleavage of a polychaete worm

S Jacobsohn

Int. J. Dev. Biol. (1999) 43: 19-26

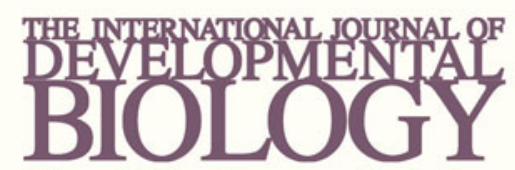

Volume 54 Nos. 6/7

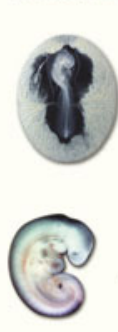

Special Issue

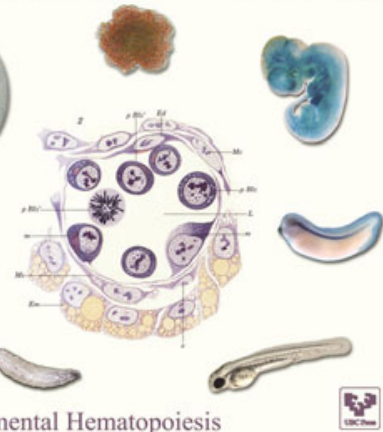

5 yr ISI Impact Factor $(2011)=2.959$

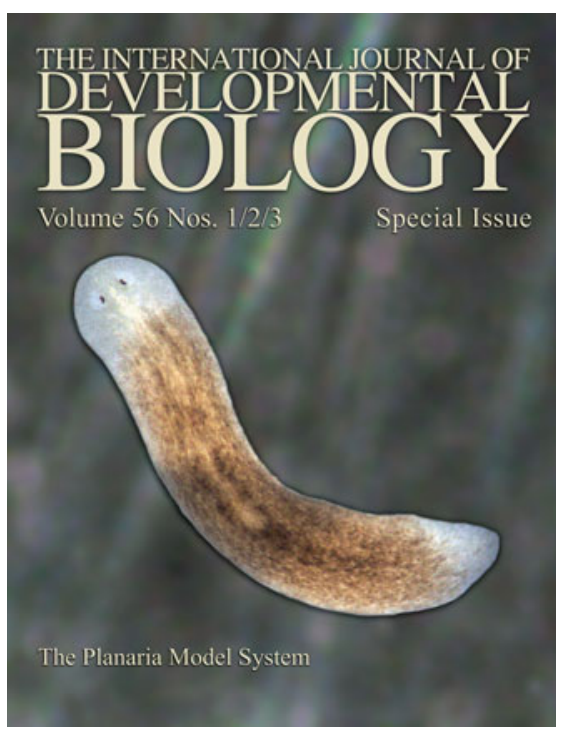

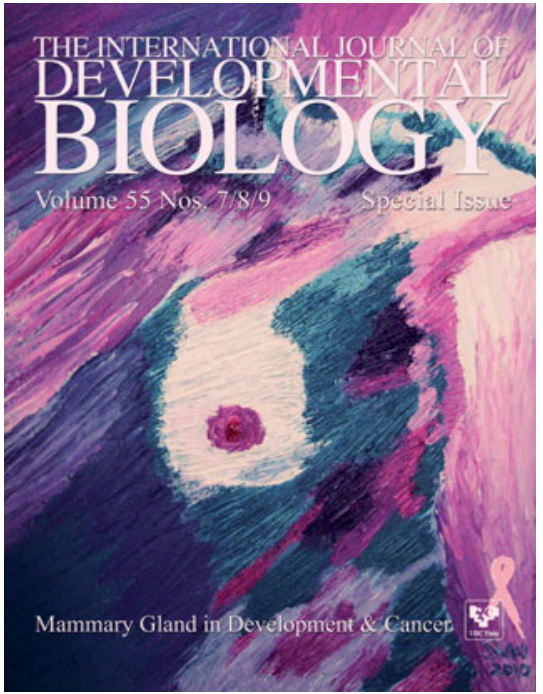

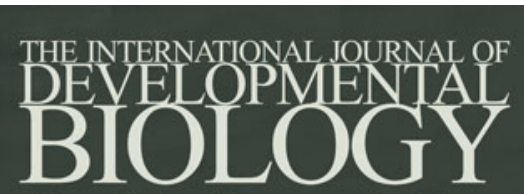

Volume 55 Nos. 4/5

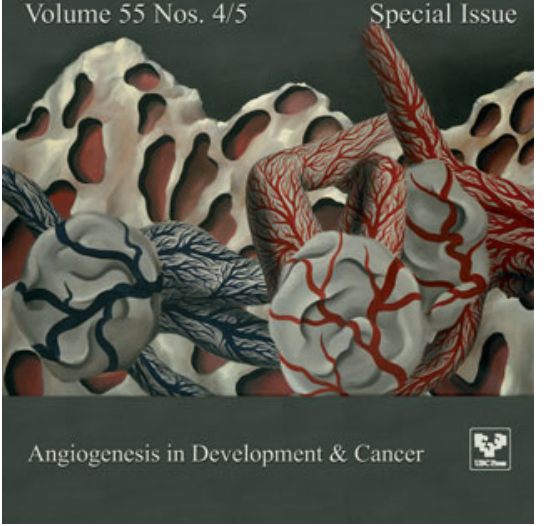

